\title{
CORRESPONDENCE
}

Mr. A.J. Roycroft has written to this Journal on a somewhat delicate subject. The item under discussion was Walter Korn's Apples to Pears on Knowledge Synthesis entry in the ICCA Journal Correspondence (Vol. 10, No. 2, p. 107), to which A.J. Roycroft has taken violent objection, both as to its being included and as to its conclusions.

As to the former point the Editors wish to point out that theirs and only theirs is the decision to include, exclude or refer to the author or other referees for improvement any and all contributions submitted to them. Hence, objections to the inclusion of an article, note or similar cannot be entertained.

As to the merits of what Korn has published, we think A.J. Roycroft's response deserves publication in full. It hinges on the fairness of pitting a human player against a necessarily inhuman database and has clearly been framed in terms of one person's experiences when preparing play against a database felt to be inimical. As such it deserves publication; its deserts are further enhanced by the statures of the parties involved: D. Michie and A.J. Roycroft.

For this reason and quite exceptionally the Editors take the opportunity to publish Roycroft's letter in full, noting that while Korn's letter may have triggered the correspondence, the text is published for its intrinsic interest rather than for its controversial topicality.

\section{PERSONAL FACTS ABOUT THE BB vS. N EXPERIMENT -- and after}

\author{
John Roycroft
}

1. In December 1983 Donald Michie approached IBM(UK) to ask for my release to assist in an as yet unidentified project to be funded, it was hoped, by an Industrial Fellowship of the Royal Society and Science and Engineering Research Council. The industrial Fellowship was in due course awarded and IBM released me under its secondment scheme. The dates of the secondment were April 25, 1984 to October 24, 1985.

2. The BB vs. N project was identified in September 1984. Ken Thompson secured the generous agreement of Bell Laboratories in New Jersey to release the data base to the Turing Institute in Glasgow. From October to January 1985 , say effectively two and a half months, I studied the endgame on my own. At no time did I have access to the data base. All my thought processes and method of proceeding were logged in 300 pages of hand-written 'protocol' that await an interested publisher.

3. Early in January 1985 I advised Donald Michie that I was ready for the first test. Position No. 1 was played on March 29, 1985 and Position No. 10 on April 30, 1985.

4. Thereafter I had immediate access to the data base. However, a chess-friendly interface designed to my specifications was not finally ready until 10 days before I faced Position No. 1 (in the second series of tests) on August 26, 1985. The last in this series was played on September 19, 1985. Therefore the second period of study was from May 1, 1985 to August 25, 1985. As I was not denied summer holiday the second study period lasted, say, a good three months.

5. The total period spent studying the two-bishops-against-knight endgame was therefore five and a half months, three of which included unrestricted, if elementary, access to the data base. Only the last ten days of the latter period were what I could call totally satisfactory, in that computer output was in conventional terse chess format, while interaction included many easily selected options. Chess positions were never displayed as diagrams. Dr. Alen Shapiro, who had many other commitments, programmed this user interface magnificently.

6. The annual Britsh Chess Championships took place in Edinburgh in August 1985. IGM Raymond Keene, present but not playing in the event, declined an invitation to travel to Glasgow to play against the data base, but FIDE Master Graham Lee, who is today General Secretary to the British Chess Federation, accepted. Subsequent experiences in inviting GMs to comment on other virgin data-base output have had disappointing results.

7. The record of the world's experts, including IGMs, who have discussed this ending in print since Horwitz and Kling in the year 1851, is a record of periphrastic repetition of the original verdict, 
namely that the Bishops cannot win a position of the Kling and Horwitz type, but they win in most cases. This is the basis of the claim that the computer data base of Ken Thompson has 'created new knowledge', since these positions, 'drawn' since 1851, are 'won' since 1983.

8. Having divided my secondment between studying this incredible endgame and living the life of the Turing Institute, of course I can play it well. Moreover I claim also to understand, and am explaining how to win it in a methodical series of articles in the pages of EG magazine.

9. A score of $80 \%$ against optimal play in such a difficult endgame is undeniably a good performance by any playing standards. Of course there are many ways to measure the improvement in performance between the first and second series of tests, and Donald Michie has selected one. For alternative methods of measurement readers must refer to a paper in the imminent Vol. 11 in the MACHINE INTELLIGENCE series.

10. The physical environment for the $l$ tests was good, but at no time in the experiment was account taken of psychological considerations. For example, at the start of the second series of tests I was poorly motivated, since I believed I had learned a number of key concepts, and this led to over-confidence. As a result I performed badly to begin with.

11. Immediately after the secondment $I$ had the enormous good fortune to stay four weeks with Ken Thompson in New Jersey. The data-base results produced then and in subsequent weeks have been reported in EG magazine and in the ICCA Journal.

12. Since July, 1987 I have now taken an early retirement and am available for more work of the same kind.

\section{FURTHER DISCUSSION ON KBBKN}

On the matter treated above, the Editors have also received what they regard as an open letter of Professor Donald Michie to the computer-chess world at large. The appeal for (IGM, according to Donald Michie) Walter Korn's help, possibly intended by Professor Michie, is herewith extended to any and all workers in the field of acquisition of relevant knowledge within well-specified domains. Barring address and saluting formulae it is published in full below.

\section{LETTER TO IGM WALTER KORN}

\section{Donald Michie}

Dear Mr Korn,

I read your article in the June 1987 ICCA with great interest and am writing to enlist your help in the experiment now under way in the Turing Institute. A brief summary of the aims of the experiment is attached, together with further detail on the chess side of the investigation. We have noted your comment that a Grandmaster would have a better chance of solving a complex endgame than an endgame specialist, but on the 13 Masters and Grandmasters we wrote to in connection with this experiment, only 3 have attempted to analyse the BBQ sub-game, and each has asked that his analysis is not published. Would you be interested in working with us, to establish whether this is a genuine example of an "ultra complex" domain, and incidentally, to throw light on an ending universally regarded as mysterious? We would be asking you to analyse the sub-game set out in the material attached, and if all went well, to check your analysis against that given by the database now under construction, and probably to play the database across the board. We would be honoured if you found that you were able to help.

Please let us have your views. 